\title{
Análise curricular do curso de medicina na perspectiva da saúde da população negra
}

\section{Maria Cristina da Conceição Oliveira ${ }^{1}$, Lenilda Austrilino e Jorge Luis de Souza Riscado ${ }^{1}$}

\author{
${ }^{1}$ Faculdade de Medicina da Universidade Federal de Alagoas, Brasil | \\ mcconceicao73@gmail.com; lenildaaustrilino@gmail.com; riscadojorgeluis@hotmail.com | \\ https://orcid.org/0000-0002-4118-3283; https://orcid.org/0000--0002-9305-3720; \\ http://orcid.org/0000-0002-7015-0798
}

\begin{abstract}
Resumo: Esse estudo visa verificar a presença da temática étnico-racial no Curso de Graduação em Medicina de uma instituição pública, investigando abordagens sobre as Relações Étnico-Raciais e da Saúde da População Negra no Projeto Pedagógico e nos conteúdos, para a matriz curricular. Metodologia qualitativa, exploratória e documental, sustentada pelas recomendações das Diretrizes Curriculares para as Relações ÉtnicoRaciais, da Política de Saúde Integral da População Negra e das Diretrizes Curriculares para o Curso de Medicina. Foi elaborada uma matriz instrumental visando organizar os dados, a partir das categorias elegíveis: Explicitação das Relações Étnico-Raciais e a Saúde da População Negra nos Fundamentos e Justificativas para a Formação Médica; Aspectos étnico-racial afro-brasileiro nos Objetivos; Habilidades e Competências; Relações ÉtnicoRaciais na Organização e no Conteúdo, sendo essa dividida em sete subcategorias. Os dados foram interpretados na perspectiva de análise de conteúdo. Os resultados demonstraram um silenciamento acerca das relações Étnico-Raciais na estrutura do Projeto Pedagógico no tocante aos fundamentos e justificativas, bem como, nos objetivos e competências para a formação médica. Nas abordagens dos conteúdos foram encontradas citações pontuais sobre as nosologias consideradas prevalentes na população negra como doença falciforme diabetes mellitus, glaucoma e hipertensão arterial, para os demais assuntos não foram identificados elementos que considerem de forma explícita o viés étnico-racial ligado à Saúde da População Negra nas ementas e nos planos de disciplinas obrigatórias da graduação. $\mathrm{Na}$ organização do curso e na matriz curricular foram identificados aspectos potencializadores possibilitando integralizar essa temática em todos os eixos formativos do curso de forma transversal.
\end{abstract}

Palavras-chave: Currículo; Etnicidade; Saúde da População Negra; Educação Médica.

\section{Curricular Analysis of the Medical Course from the Perspective of the Health of the Black Population}

\begin{abstract}
This study aims to verify the presence of ethnic-racial themes in the Medical Graduation Course of a public institution, investigating approaches on Ethnic-Racial Relations and Health of the Black Population in the Pedagogical Project and in the contents of the curricular matrix. Qualitative, exploratory, and documentary methodology, supported by the recommendations of the Curricular Guidelines for Ethnic-Racial Relations, the Integral Health Policy of the Black Population, and the Curriculum Guidelines for the Medicine Course. An instrumental matrix was elaborated to organize the data, from the eligible categories: explicitation of Ethnic-Racial Relations and the Health of the Black Population in the Foundations and Justifications for the Medical Formation; Afro-Brazilian ethno-racial aspects in the Goals; Skills and Skills; Ethnic-Racial Relations in Organization and Content, which is divided into seven subcategories. The data were interpreted from the perspective of content analysis. The results showed a silencing about Ethnic-Racial relations in the structure of the Pedagogical Project regarding the fundamentals and justifications, as well as in the objectives and competencies for medical training. In the content approaches, specific citations were found on the nosologies considered prevalent in the black population, such as sickle-cell disease, diabetes mellitus, glaucoma, and arterial hypertension, for the other subjects there were no elements that explicitly considered the ethnic-racial bias linked to Black population in the menus and plans of compulsory subjects of graduation. In the organization of the course and in the curriculum matrix, potential aspects were identified, making it possible to integrate this theme in all the formative axes of the course in a transversal way.
\end{abstract}

Keywords: Curriculum; Ethnicity; Health of the Black Population; Medical Education. 


\section{Introdução}

O contexto social brasileiro é formado por uma diversidade étnico-racial e cultural, representadas pelas culturas europeia, indígena e africana, o que caracterizou a sociedade como multicultural, com predominância dos afrodescendentes, devido ao grande número de pessoas dessa descendência trazidos para o Brasil na condição de escravos. Contudo, a ideologia da identidade coletiva e única, permeada na sociedade brasileira, contribuiu fortemente para o não reconhecimento dessa heterogeneidade e da diversidade de relações existente no País (Nascimento, 2003).

As relações étnico-raciais no Brasil foram pautadas no sistema colonialista em que a hierarquia de raça levou a sobreposição da cultura branco-eurocêntrica e permitiu a invisibilidade, de maneira intencional, das demais matrizes étnicas e raciais, cujas histórias e culturas, são fatos que não se discutem, não são notados e/ou não querem fazer notar.

No caso dos afrodescendentes trazidos para o Brasil, a invisibilidade de sua história e de sua cultura, se constitui em uma das estratégias da escravidão, visando destruir a memória coletiva desse seguimento populacional e, de justificar relações étnico-raciais desiguais estabelecidas no campo econômico, sociocultural, político e racial (Munanga, 2015). No contexto atual essas desigualdades, traduziram-se em arranjos políticos e sociais que limitam oportunidades e formas de expectativa de vida da população negra (Brasil, 2013).

Questionar sobre as diferenças étnico-raciais, na contemporaneidade, é necessário, visto que cada vez mais casos de autodefinição étnica e racial, contraria a teoria de identidade coletiva única e ressalta o direito à diferença. Fato evidenciado pelo censo do Instituto Brasileiro de Geografia e Estatística - IBGE, divulgado em 2010, mostrou que a população negra, composta pelos pretos e pardos, representa $50,7 \%$ da população brasileira.

A luta do movimento negro fez-se protagonista em diversas esferas, como educação, cultura, saúde, sendo que esta última contribuiu para tornar constitucional que "saúde é um direito de todos e um dever do Estado" (Brasil, 1988). A consolidação do Sistema Único de Saúde (SUS) levou ao norteamento de diretrizes para formação dos profissionais da saúde, de modo a adequar às perspectivas de acomodação das diversas realidades e demandas relacionadas ao momento histórico, social, econômico e cultural da sociedade (Batista e Gonçalves,201; Pereira e Lages, 2013).

Como norteador da formação e da prática dos agentes de saúde, o SUS tem buscado instituir políticas, nas quais busca alinhar orientações para a educação em saúde que atendam aos paradigmas emergentes, dentre as quais se encontra Política de Saúde Integral População Negra - PNSIPN (Brasil, 2013). Esta tem como objetivo a promoção e equidade em saúde, com planejamento de ações tendo em vista o maior cuidado na área da atenção à saúde desse segmento populacional, que ainda carrega nesse campo a marca das desvantagens nas condições de vida e da falta de acesso aos serviços de saúde.

Em relação às políticas educacionais, a legislação vigente, busca reunir uma série de exigências que estimula o desenvolvimento de processos de compreensão e de reconhecimento da identidade de matriz afro e afro-brasileiras de forma positiva, bem como a construção de uma ética que respeite e considere as diferenças tanto na política como nas práticas pedagógicas.

Neste contexto, se destaca as Diretrizes Curriculares Nacionais para a Educação das Relações Étnico-raciais e para o Ensino de História e Cultura Afro-Brasileira e Africana DCNERER (Brasil, 2004), que orienta a inserção de conteúdos sobre a história e cultura africana em todos os níveis de ensino.

Para a formação médica, as Diretrizes Curriculares Nacionais para o curso de medicina, propuseram ajustes que focalizam a necessidade de uma formação que considere a diversidade étnico-racial a partir do conhecimento sobre as realidades históricas e culturais da matriz afro-brasileira e sua influência nos processos de saúde-doença (Brasil, 2014). 
Esses ajustes buscam atender, na área da educação, as demandas da população afrodescendente, no que se refere às políticas de ações afirmativas, ou seja, de reparações e de reconhecimento e valorização de sua história, cultura e identidade. Para a formação médica, particularmente, entende-se que a educação profissional nesse campo, deve alinhar valores que possibilite ir além do exercício de uma medicina competente tecnicamente, bem como a características peculiares como: o compromisso ético e à concepção ampliada de saúde, onde cuidar é valorizar, é criar vínculo e se responsabilizar pela integralidade das ações (Gomes, 2011).

A inserção das relações étnico-raciais na perspectiva da população negra no currículo médico parece ser uma urgência, uma vez que, para esse seguimento populacional, os indicadores de saúde, quando desagregado por raça cor, têm revelado que qualidade de vida e, consequentemente, a saúde encontram-se abaixo, com uma significativa diferença, em alguns casos, quando comparado com outros seguimentos étnicos (Brasil, 2014).

A lacuna da temática nos currículos e programas dos cursos de formação dos profissionais médicos demonstra que, mesmo havendo legislação que disponha sobre a inclusão de estudo dessa temática no ensino superior, isso não garante sua efetividade. Segundo Monteiro (2016), "os cursos da área de saúde pouco ou nada têm feito no sentido de considerar o tema em questão como conteúdo pertinente à formação dos novos profissionais".

Isso significa que, o fato das políticas afirmativas avançarem não garante que o reconhecimento e a implementação das mesmas sejam uma realidade. Diante desta preocupação, esse estudo teve como objetivo verificar a presença da temática étnicoracial no Curso de Graduação em Medicina. Para tal, recorreu-se à análise da estrutura do PPC, nas dimensões política e pedagógica, relacionando-as com os contextos emergentes das relações étnico-raciais na perspectiva da saúde da população negra.

\section{Metodologia}

Estudo documental, de caráter exploratório, numa perspectiva qualitativa, visando responder aos questionamentos: 1) as Relações Étnico-Raciais para o segmento populacional afro e afro-brasileiro estão sendo contempladas no Projeto Político Pedagógico do Curso (PPC)? 2) Em que áreas e, em que os conteúdos da matriz curricular do curso de medicina contemplam as Relações étnico-raciais e Saúde da População Negra? 3) Quais potencialidades e desafios existem para inserção das Relações ÉtnicoRaciais?

A análise documental constitui uma técnica importante, seja complementando informações obtidas por outras técnicas, seja desvelando aspectos novos de um tema ou problema (Ludke e André, 1986).

O estudo em foco ateve-se à análise crítica do Projeto Político Pedagógico do Curso (PPC) de graduação em medicina da Faculdade de Medicina (FAMED) de uma IES pública do nordeste brasileiro, tomando como referência os seguintes documentos: a) Diretrizes Curriculares para o Curso de Medicina (Brasil, 2014); b) Diretrizes Curriculares para Educação das Relações Étnicos-Raciais (Brasil, 2004); c) Política de Saúde Integral da População Negra (Brasil, 2009).

O PPC de medicina, versão 2013, disponível no site da FAMED está organizado em cinco capítulos. Pautando-se nas Diretrizes Curriculares para o curso de medicina instituída em 2001 e, em legislações do SUS. Foi produzido de forma coletiva por uma equipe formada por representantes do corpo docente, técnicos, discentes, a partir das necessidades de adequar o curso as demandas emergentes, as mudanças e exigências legais para a formação médica. 
A análise do conteúdo do PPC buscou identificar indícios de abordagens sobre a SPN na contextualização e nas intencionalidades, tanto na dimensão política - aqui representada pelos fundamentos, justificativas, objetivos, perfil do egresso, competências e habilidadesquanto na dimensão pedagógica representada pela matriz curricular, composta por planos de ensino das disciplinas; objetivos de aprendizagens e conteúdo.

Para realizar a análise do PPC foi necessário inicialmente elaborar categorias e, a partir dos documentos analisados, as unidades de registro (UR) para cada categoria. Foram estabelecidas três categorias. Categoria 1: Explicitação das relações étnicos raciais e a saúde da população negra, nos fundamentos e justificativa para a formação médica. Categoria 2: Aspectos étnico-racial afro-brasileiro nos objetivos, habilidades e competências. Categoria 3: relações étnico-raciais na organização e no conteúdo curricular.

Foi realizado um levantamento nos documentos de referência - DCN para o Curso de Graduação em Medicina, nas DCN para Educação das Relações Étnico-Raciais e na Política de Saúde da População Negra, analisando artigos e parágrafos na perspectiva de elaborar as UR e de identificar os aspectos relacionados à saúde da população negra. Em seguida, a estrutura do PPC e a matriz curricular do curso de medicina da FAMED foram analisadas, visando identificar em que áreas e conteúdos as relações étnico-raciais, para a formação médica na perspectiva da saúde da população negra, estavam contempladas.

Para a construção dos dados foi elaborada uma matriz instrumental, objetivando um norteamento para a obtenção das informações com categorias prévias, elegidas a partir do referencial teórico e descritas no quadro 1 :

Tabela 1. Categorias e Subcategorias

\begin{tabular}{|c|c|c|c|c|c|c|}
\hline \multicolumn{7}{|c|}{$\begin{array}{c}\text { Categoria 1- Explicitação das Relações Étnico-Raciais e a Saúde da } \\
\text { População Negra (SPN) nos Fundamentos e Justificativas para a Formação } \\
\text { Médica }\end{array}$} \\
\hline \multicolumn{7}{|c|}{$\begin{array}{l}\text { Elementos que consideram a abordagem ao perfil epidemiológico, condições de } \\
\qquad \text { vida, e realidade social da PN }\end{array}$} \\
\hline \multicolumn{7}{|c|}{$\begin{array}{c}\text { Categoria } 2 \text { - Aspectos étnico-racial afro-brasileiro nos objetivos, } \\
\text { Habilidades e Competências }\end{array}$} \\
\hline \multicolumn{7}{|c|}{$\begin{array}{l}\text { Elementos que valorizem os aspectos éticos/humanísticos considerando o viés } \\
\text { racial para a formação médica }\end{array}$} \\
\hline \multicolumn{7}{|c|}{$\begin{array}{c}\text { Categoria } 3 \text { - Relações Étnico-Raciais na Organização e no conteúdo } \\
\text { curricular }\end{array}$} \\
\hline \multicolumn{7}{|c|}{$\begin{array}{l}\text { Elementos que considere o viés étnico racial nos temas sobre da SPN na } \\
\text { graduação em medicina }\end{array}$} \\
\hline \multicolumn{7}{|c|}{ Subcategorias } \\
\hline $\begin{array}{l}\text { Contextuali } \\
\text { zação da } \\
\text { SPN }\end{array}$ & $\begin{array}{l}\text { Humaniz } \\
\text { ação } \\
\text { SPN }\end{array}$ & $\begin{array}{l}\text { Política } \\
\text { de SPN }\end{array}$ & $\begin{array}{l}\text { Nosologia } \\
\text { da SPN }\end{array}$ & $\begin{array}{l}\text { Semiologia } \\
\text { atendimento } \\
\text { da PN }\end{array}$ & $\begin{array}{l}\text { Farmacolo } \\
\text { gia e } \\
\text { Perspectiva } \\
\text { da SPN }\end{array}$ & $\begin{array}{l}\text { Ética, } \\
\text { Bioética } \\
\text { e } \\
\text { Espiritual } \\
\text { idade }\end{array}$ \\
\hline
\end{tabular}

Os dados foram discutidos na perspectiva da análise de conteúdo, utilizando os referenciais das relações étnico-raciais e da política de saúde integral da população negra, com o propósito de escoimar, em cada texto, o núcleo emergente que atendesse aspectos objetivos e subjetivos contidos no PPP, nas dimensões política e pedagógica, buscando desvelar questões relacionadas à temática Saúde da População Negra (SPN) durante a formação. 


\section{Resultados}

O PPC analisado apresenta uma proposta de ensino ancorada nas DCN de medicina e nas políticas de saúde do SUS. Entretanto, não foi apontado explicitamente, referencial sobre as relações étnico-raciais, nem sobre a saúde da população negra.

Para a análise dos fundamentos e justificativas para a formação médica foi considerada uma abordagem que permitisse a visibilidade do perfil epidemiológico, condições de vida, e realidade social da população negra na apresentação da realidade e a relevância do debate sobre a temática étnico-racial para o curso de medicina, descritas no Projeto Pedagógico.

Os dados encontrados no PPC pesquisado ressaltam aspectos sobre a geografia local, a epidemiologia e os dados sócio demográficos populacionais, os determinantes sociais e as necessidades de saúde. No entanto, essa apresentação é feita de forma homogênea sem nenhuma contextualização acerca das diferenças raciais e aos impactos e necessidade de saúde da população negra.

Para o ensino superior, as $\mathrm{DCN}$ propõem a inserção da temática racial na Atenção em Saúde, o artigo $5^{\circ}$ descreve:

[...] o graduando será formado para considerar sempre as dimensões da diversidade biológica, subjetiva, étnico-racial, de gênero, orientação sexual, socioeconômica, política, ambiental, cultural, ética e demais aspectos que compõem o espectro da diversidade humana que singularizam cada pessoa ou cada grupo social [...] (Brasil, 2014).

Monteiro (2016) ressalta que, dentro do processo de reconhecimento dos determinantes sociais de saúde, que constituem os desafios da Saúde Pública, é preciso considerar, raça-etnia no enfrentamento das razões que determinam a produção e reprodução das desigualdades sociais na sociedade brasileira.

Nos dados sobre o perfil epidemiológico da população brasileira, fica evidente que a população negra ainda se encontra em considerável situação de vulnerabilidade, com condições de saúde precárias, com índices elevados no que diz respeito às doenças crônicas e infecciosas (IBGE, 2014). Essa realidade possivelmente influenciada pelo o racismo institucional, que ainda persiste "nas estruturas de organização da sociedade e nas instituições" (Barbosa, 2017), dificulta a qualificação de profissionais com o propósito de minimizar essas iniquidades.

Além disso o PPC em análise menciona, entre as competências, a concepção de educação que tem a práxis como referencial, a partir de uma proposta de formação críticoreflexiva do egresso, demonstrando o compromisso da instituição em desenvolver, não apenas competências técnicas, mas também a construção de uma sociedade baseados em princípios éticos e humanos.

Esta concepção está presente nos objetivos, quando afirmam:

Formar médicos [...] dentro dos princípios éticos e humanos (PPC, p.44).

Propiciar uma formação generalista [...] priorizando a relação médicopaciente com senso crítico, fazendo-se transformador da realidade (PPC, 44).

Propiciar diferentes cenários de ensino aprendizagem, permitindo o aluno conhecer e evidenciar contextos variados de organização social, de trabalho e de cuidados, contribuindo para a sua formação técnica, política e humanista com valores orientados para a cidadania (PPC, p.44).

Propiciar uma análise crítica permanente e dinâmica da sociedade contribuindo para as transformações exigidas (PPC, p.44).

Ter como referência o trabalho no Sistema Único de Saúde - SUS para o processo ensino aprendizagem (PPC, p.44). 
Ao orientar as competências para que estejam subsidiadas por elementos que valorizem os aspectos éticos e humanísticos, fica evidente o cuidado para que o PPC seja coerente com os valores preconizados pela instituição, em construir uma sociedade mais justa e comprometida com os princípios do SUS.

O PPC apresenta nas habilidades e competências referências explícitas, quanto à preparação de profissionais para atender a questão da "diferença", no entanto, não menciona os aspectos étnico-raciais e suas singularidades relacionadas aos afrobrasileiros, conforme descrito a seguir:

\section{[...] capacidade de lidar com as diferenças [...] (PPC p. 61).}

Desenvolver diálogo claro e coerente, considerando aspectos sócio culturais do paciente e da família [...] (PPC p. 63).

As informações descritas no documento pesquisado demonstram uma explícita intenção institucional em garantir uma formação médica voltada à cidadania, muito embora, não se tenha identificado menção à necessidade de reflexão crítica sobre o modo como as relações étnico-raciais acontecem.

Os dados evidenciados na pesquisa nacional de saúde de 2013 apontaram que as condições de saúde do negro comparadas às dos não negros, ainda são consideradas ruins demonstrando que o cuidado à saúde dessa população ainda se encontra precário (BGE, 2014). São realidades que tornam clara a necessidade de desenvolver competências e habilidades que contemplem a dimensão étnico-racial.

Para Henriques Camelo et al. (2013), a possibilidade de solução das questões de saúde encontra-se nos recursos humanos, pois através de sua influência na atenção e na terapêutica prestadas aos indivíduos e coletividade, podem ser capazes de interferir positivamente na modificação das condições de vida e de saúde da população.

A Resolução CNE/CP 01/2004 em seu artigo 5ำ prevê, para as relações étnico-raciais, que os conteúdos abordados devem colaborar para a correção de posturas e atitudes que implicam desrespeito e discriminação. Assim, os temas abordados sobre o processo saúde doença da PN, formação em saúde, devem servir para a reflexão e esclarecimento de relações, condutas, estilo de vida, trabalho, valores culturais. A discussão sobre a temática é também uma forma de educar para que "desconstruam estigmas e preconceitos, fortaleçam uma identidade negra positiva e contribuam para a redução das vulnerabilidades" (BRASIL, 2013).

A organização curricular explicita a dinâmica do curso, no que se refere as disciplinas, a articulação entre elas e as atividades a serem desenvolvidas para oferecer uma formação adequada. Seguindo as DCN, a estrutura do curso de medicina deve:

Artigo 29: A estrutura do Curso de Graduação em Medicina deve: [...]

III - incluir dimensões ética e humanística, desenvolvendo, no aluno, atitudes e valores orientados para a cidadania ativa multicultural e para os direitos humanos (BRASIL, 2014);

IV - promover a integração e a interdisciplinaridade em coerência com o eixo de desenvolvimento curricular, buscando integrar as dimensões biológicas, psicológicas, étnico-raciais, socioeconômicas, culturais, ambientais e educacionais (BRASIL, 2014).

A operacionalização dessa dinâmica formativa, propostas para os conteúdos a serem inseridos na matriz curricular, favorece o comprometimento das instituições formadoras com um ensino baseado no respeito às diferenças étnicas, e com a PNSIPN.

As DCN orientam que se inclua a etnicidade nas anamneses, conforme previsto nos descritores da Atenção às necessidades de saúde individual, artigo 12:

\section{I - Realização da História Clínica preve:}

f) identificação dos motivos ou queixas, evitando julgamentos, considerando

o contexto de vida e dos elementos biológicos, psicológicos, 
socioeconômicos e a investigação de práticas culturais de cura em saúde, de matriz afro-indígena-brasileira e de outras relacionadas ao processo saúdedoença;

\section{II - Realização do Exame Físico:}

c) postura ética, respeitosa e destreza técnica na inspeção, apalpação, ausculta e percussão, com precisão na aplicação das manobras e procedimentos do exame físico geral e específico, considerando a história clínica, a diversidade étnico-racial, de gênero, de orientação sexual, linguístico-cultural e de pessoas com deficiência; (BRASIL, 2014)

Para verificar a presença dessa temática no conteúdo programático, foram analisadas as ementas e planos das 34 disciplinas presentes na matriz curricular do curso de medicina em estudo. Visando auxiliar a análise, 23 unidades de registro foram agrupadas em 7 subcategorias: Contextualização da Saúde da População Negra; Humanização e SPN Política de Saúde da PN; Nosologia da SPN; semiologia e atendimento da PN; Farmacologia, perspectiva e SPN; Ética, bioética e espiritualidade.

Para estas subcategorias foram estabelecidas unidades de registros ligadas a aspectos relacionados a saúde das populações afro e afro-brasileira, bem como a cultura, determinantes sociais, condições de vida e epidemiologia na perspectiva da problematização sobre a identidade brasileira influenciada pelos arquétipos afro e afrobrasileiro. Foram consideradas também, a postura crítica e reflexiva frente às crenças, atitudes, valores discriminatórios e preconceituosos, cuidado centrado na pessoa, família ou comunidade, população livre de estereótipos, racismo e seus efeitos pessoais, interpessoais e institucionais, alteridade e a relação médico-paciente, bioética, bem como suas razões e emergência, as especificidades da saúde, compreensão e visão crítica antirracista quanto aos fatores desencadeadores e determinantes do racismo na atenção à saúde.

Além destas unidades de registro foram consideradas as doenças de condições genéticas, as doenças adquiridas pelas condições de vida desfavoráveis, as doenças agravadas pelas condições de acesso e condições fisiológicas que sofrem interferências ambientais e evoluem para doenças. Esta abordagem aparece em sua maioria, vinculadas as disciplinas Semiologia, Propedêutica, Saúde do Adulto e do Idoso, Saúde da Mulher, Saúde da Criança e do Adolescente, Psiquiatria de Urgência, Saúde e Sociedade, Medicina Legal do Eixo Teórico-Prático-Integrado.

Durante a análise buscou-se elementos que considerassem a peculiaridade na comunicação, a inclusão do quesito cor na perspectiva da identificação étnico-racial e percepção da concepção de saúde-doença na cosmovisão mítica e religiosa afrobrasileira, avaliação genética e das condições socioeconômica.

Em relação aos protocolos terapêuticos e processos de distribuição de fármacos pela rede SUS de medicamento, que se relacione com as políticas de atenção farmacêutica à saúde - ligadas à diversidade, parecem ser ignoradas.

Para a subcategoria Ética, Bioética e Espiritualidade refere-se aos indícios da cosmovisão africana na perspectiva do cuidado. Não foi observada referência a unidade de registro elencada para ela.

Diante da análise das 34 disciplinas contidas no Eixo teórico-prático 30 apresentam conteúdos capazes de integralizar as temáticas descritas nas unidades de registro. Entre as 23 unidades de registro elencadas, 21 foram identificadas considerando inferências implícitas nos assuntos abordados. No que se refere às nosologias consideradas prevalentes na população negra, apenas as de condições genéticas apareceram com abordagens pontuais, porém, nenhuma delas trouxe explicitamente o viés racial em seus conteúdos. 


\section{Conclusões}

A pesquisa identificou que há um silenciamento no PPC, do curso de medicina estudado, sobre a realidade da Saúde da População Negra na estrutura, organização e nas intencionalidades descritas no PPC e nos conteúdos, embora haja, algumas referências pontuais de temas sobre doenças, consideradas científica e geneticamente, prevalentes na PN, não há evidências explícitas sobre discussões que considere o viés racial.

Por outro lado, foi observado que a instituição possui uma organização curricular fundamentada em paradigmas que permitem aproximações com as Relações ÉtnicoRaciais, com possibilidades significativas de inserção transversal da temática, necessitando adequações e ajustes na organização de sua matriz curricular, bem como nas ementas e planos das disciplinas a fim de possibilitar a integralização dessa temática em todos os eixos formativos do curso.

As urgências contextuais evidenciadas pelos indicadores sociais e, as orientações legais apontam para a necessidade de inserção de temas sobre a Educação das Relações Étnico-Raciais, História afro-brasileira e Saúde da População Negra na formação médica. Fica evidenciado a necessidade de a instituição de ensino propor estratégias de reforma curricular que permitam avançar na integralização da temática descritas no Projeto Pedagógico do Curso.

Os resultados mostram a necessidade de acrescentar informações relacionadas à demografia, epidemiologia e as condições de saúde da população negra, trazendo dados desagregados por raça/cor, nos textos referente aos objetivos e ao perfil do egresso de forma a evidenciar referências acerca da diversidade étnico-racial afro-brasileira. $\mathrm{Na}$ técnica, descrever sobre a identificação de doenças e na elaboração dos planos terapêuticos incluindo a questão racial. Nas habilidades e competências de dimensão relacional, e de identificação dos contextos discutir aspectos éticos e legais que possam levar a reflexão do viés ideológico sobre a assistência à saúde dessa população a partir, dos eixos relacionados à Atenção em Saúde Individual e Coletiva.

A pesquisa qualitativa na modalidade documental, por se constituir um método crítico possibilitou traçar o viés ideológico presente nos documentos fontes pesquisadas, proporcionando identificar as ausências e potencialidades, sobre aspectos relacionados a saúde da população negra, na formação médica da instituição estudada. A análise dos documentos de referência apontou os caminhos a seguir para suprir as lacunas, aprofundar o conhecimento, norteando proposições e estabelecendo recomendações a serem implementadas.

\section{Referências}

Barbosa, Leonardo et al. (2017). Racismo institucional e as oportunidades acadêmicas nas IFES. Revista Brasileira de Ensino Superior, v. 3, n. 3, p. 80-99,

Batista, Karina Barros Calife; Goncalves, Otília Simões Janeiro. (2011). Formação dos profissionais de saúde para o SUS: significado e cuidado. Saúde e Sociedade, São Paulo, v. 20, n. 4, p. 884-899, Dec.

Brasil. (2010). Instituto Brasileiro de Geografia e Estatística - IBGE. Censo Demográfico. Resultados do universo. Agregados por setores censitários IBGE. 2010.

Brasil. (1988) Constituição (1988). Constituição da República Federativa do Brasil. Brasília/DF: Senado Federal.

Brasil. (2017) Índice de vulnerabilidade Juvenil à Violência 2017 - Desigualdade Racial Municípios com mais de 100 mil habitantes. SNJ/PR. São Paulo.

Brasil. (2013) Instituto Brasileiro de Geografia e Estatística - IBGE. Síntese de Indicadores Sociais - Uma análise das condições de vida da população brasileira. IBGE. Rio de Janeiro. 
Brasil. (2014) Instituto de Pesquisa Econômica Aplicada. Situação social da população negra por estado. IPEA.

Brasil. (2001) Ministério da Saúde. Secretaria de Políticas de Saúde. Manual de doenças mais importantes, por razões étnicas, na população Brasileira afro-descendente. Brasilía/DF. MS.

Brasil. (2013) Plano Nacional de Implementação das Diretrizes Curriculares Nacionais para Educação das Relações Etnico-raciais e para o Ensino de História E Cultura Afrobrasileira e Africana. Secretaria de Educação Continuada. Alfabetização, Diversidade e Inclusão: MEC/SECADI.

Brasil. (2013) Política Nacional de Saúde Integral da População Negra: uma política do SUS. 2 ed. Brasília/DF. Ministério da Saúde.

Brasil. (2011) Racismo como determinante social em saúde. SEPPIR/PR. Brasília/DF.

Brasil. (2004) Resolução no 01 de 17 de junho 2004. Institui Diretrizes Curriculares Nacionais para a Educação das Relações Étnico-Raciais e para o Ensino de História e Cultura Afro-Brasileira e Africana. MEC/CNE/CP.

Brasil. (2014) Resolução no 03 de 03 de junho 2014. Institui Diretrizes Curriculares Nacionais do Curso de Graduação em Medicina. MEC/CNE/CES.

Gomes, Andréia Patrícia et al. (2011) Transformação da educação médica: é possível formar um novo médico a partir de mudanças no método de ensinoaprendizagem. Rev bras educ méd, v. 35, n. 4, p. 557-66.

Henriques Camelo, Silvia Helena; Saporiti Angerami, Emília Luigi. () Competência profissional: a construção de conceitos, estratégias desenvolvidas pelos serviços de saúde e implicações para a enfermagem. Texto \& Contexto Enfermagem, v. 22, n. 2.

Lüdke, Menga; André, Marli Eda. (1986) Pesquisa em educação: abordagens qualitativas.

Monteiro, Rosana Batista. (2016) Educação permanente em saúde e as Diretrizes Curriculares Nacionais para Educação das relações étnico-raciais e para ensino de História e Cultura Afro-Brasileira e Africana. Saúde e Sociedade, v. 25, n. 3, p. 524534.

Munanga, Kabengele. (2015) Negritude-usos e sentidos. Coleção cultura negra e identidades. Autentica.

Nascimento, Elisa Larkin. (2003) O sortilégio da cor: identidade, raça e gênero no Brasil. Selo Negro.

Pereira, Ingrid; Lages, Itamar. (2013) Diretrizes curriculares para a formação de profissionais de saúde: competências ou práxis? Trabalho, educação e saúde, v. 11, n. 2, p. 319-338.

Universidade Federal De Alagoas. (2013) Faculdade de Medicina. Projeto Pedagógico do Curso. 